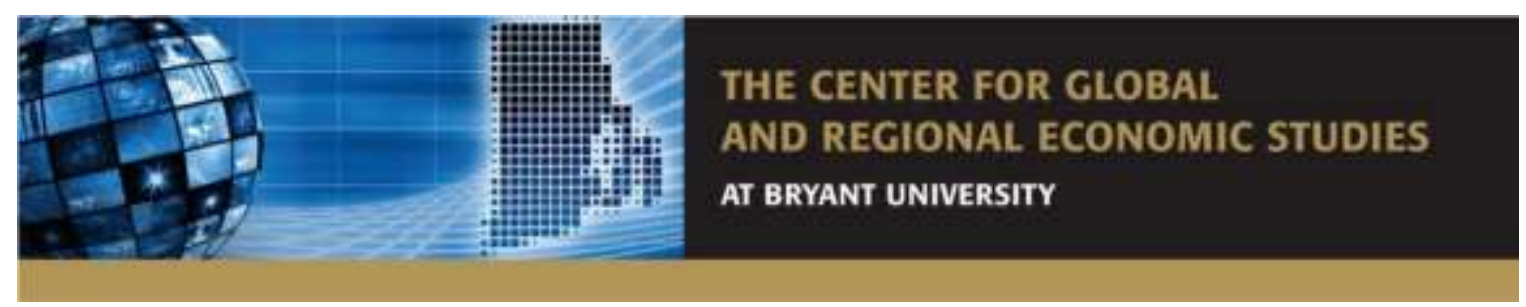

WORKING PAPER SERIES

\title{
The Relationship between Economic Growth and Environmental Degradation: Exploring Models and Questioning the Existence of an Environmental Kuznets Curve
}

\author{
Jonathan Skaza \\ Economic Student \\ Bryant University \\ Smithfield, RI \\ jskaza@bryant.edu \\ Brian Blais, PhD \\ Science and Technology Department \\ Bryant University \\ Smithfield, RI \\ bblais@bryant.edu
}

Working Paper 2013-05

October 2013 
The Working Paper Series publishes original research of Bryant University faculty associated with the Center for Global and Regional Economic Studies.

\title{
The Relationship between Economic Growth and Environmental Degradation: Exploring Models and Questioning the Existence of an Environmental Kuznets Curve
}

\begin{abstract}
In this paper, we explore a variety of models attempting to explain the pollution-income relationship (PIR). There has been much literature addressing the notion of an environmental Kuznets curve (EKC). Many researchers find an EKC relationship for certain pollutants, while others do not find evidence of an EKC relationship. There is also literature formally critiquing the EKC. We employ cross-sectional, panel, and time-series analysis to add insight into the relationship between economic growth and environmental degradation, a research area that is far from consensual and that has practical implications. We ultimately find that the clearest case of an EKC effect in our study arises in the analysis of organic water pollution, while there is modest evidence suggesting an EKC effect with regard to $\mathrm{CO}_{2}, \mathrm{NO}$, and methane. We also present ample evidence suggesting an anti-EKC effect for PM10. Our analysis causes us to question the existence of an EKC effect throughout the environment in general.

Keywords: Kuznets, environmental economics, economic growth, pollution JEL Classifications: Q53, Q56
\end{abstract}

Received support from the Center for Global and Regional Economic Studies. 


\section{Introduction}

Does economic growth damage the environment or does the environment improve when a country becomes more economically prosperous? Intuition could lead one to take either side on the issue. For example, it would not be unreasonable to believe that with economic growth comes more industry and ultimately more pollution. On the contrary, it seems possible that economic growth may result in innovation and greener technologies-not to mention a greater preference for a cleaner environment from the richer population. Perhaps neither is true, indicating that the interplay between economic growth and environmental quality is more complex, or perhaps fundamentally random. The answer to this introductory question seems relevant, applicable, and worthwhile to decision-makers of developing countries (among many others), yet there is no clear-cut consensus on an answer. In this paper, we hope not to add to the confusion, but instead to provide clarity to the relationship between economic growth and environmental quality through a series of empirical approaches.

Many environmentalists have claimed that environmental degradation is a necessary cost of economic growth. Beginning in the 1990s, however, many researchers have proposed a relationship modeled by an environmental Kuznets curve (EKC). Unlike the environmentalists who posit a pollution-income relationship (PIR) that is monotonically rising, proponents of the EKC outline a relationship that takes the shape of an inverted-U. That is, at low levels of income, economic growth is associated with environmental deterioration, but, at a certain level of income (i.e., turning point level) economic growth is actually associated with improved environmental quality. To be precise, environmental pressure increases at a faster rate than income during early stages of economic development and eventually slows down relative to income growth as a country approaches higher levels of real GDP. 
The first empirical study on the EKC - though the term EKC was never used in the associated paper-dates back to Grossman and Krueger (1991). Panayotou (1993) is credited with having been the first to coin the term "environmental Kuznets curve". Interestingly, however, the Kuznets curve dates back to Kuznets (1955), who used the inverted-U shaped framework to describe the relationship between income inequality and income. Both the EKC and the original Kuznets curve are premised on the fundamental idea that as an economy grows, some measure of the quality of life (e.g., the environment or the distribution of income) will initially worsen before improving (Pearson 1994, p. 201 and Munasinghe 1999, p. 95 from Lieb, 2003).

The works of Grossman and Krueger (1991) and the many subsequent researchers who have contributed to the EKC literature have fundamentally changed the way that governments and global institutions, as well as academicians, view the PIR. Accordingly, Lieb (2003) writes that "pollution is considered as only a transitional phenomenon in the course of economic growth" (p. 1). Beckerman (1992) goes so far as to write that "in the long run, the surest way to improve the environment is to become rich" (p. 491). This is a far cry from the environmentalists fretting the obligatory environmental destruction powered by the engine of economic growth. This is not to say, however, that the EKC does not have its critics-for researchers are far from unanimity with regard to their views on the EKC. What follows is a subsection on many of the criticisms of the EKC literature, many of which we hope to address, clarify, and disambiguate throughout the remainder of the paper.

\section{Criticisms of the EKC}

In writing on their dynamic simulation approach to the EKC, Anderson and Cavendish (2001) critique the standard 'comparative statics' framework to analyzing the PIR: "In reality, 
estimating the economic and physical effects of environmental policies requires us to move beyond this 'comparative statics' framework [which Anderson and Cavendish claim as being the standard approach], since although it has yielded several insights for policy, it is restrictive" (p. 721). In the traditional static approach, emissions or concentrations are dependent only on per capita income. No attention is paid to policy independent of income or to the technical changes and substitutions that policies induce (Anderson and Cavendish, 2001).

Another criticism of the EKC literature lies in the data. The most straightforward wayand the traditional way, in fact - to model the EKC or, more appropriately, the PIR, is to collect data on some certain pollutant (i.e. $\mathrm{SO}_{2}, \mathrm{SPM}, \mathrm{NO}_{x}, \mathrm{CO}$, etc.) and on per capita income. The researcher then estimates the model, or a variation of the model:

$$
\text { (1) } P_{i t}=\alpha+\beta_{1} Y_{i t}+\beta_{2} Y_{i t}^{2}+\beta_{3} Y_{i t}^{3}+\beta_{4} X_{i t}+\varepsilon_{i t}
$$

where $P$ is a measure of pollution, measured in emissions per capita or as a concentration, $Y$ is GDP per capita, adjusted to be on par with some base year, $i$ indexes the country or measuring station, $t$ indicates time, $X$ is used to control for other relevant explanatory variables, and $\varepsilon$ is the error term (Lieb, 2003). Unfortunately, this type of specification is not immune to poor data quality, which some argue applies to EKC data. For one, emissions data are not measured, but are estimated (leaving room for error) (Lieb, 2003). Furthermore, concentrations are not concrete numbers, but vary widely over time and space (Lieb, 2003). Lieb (2003) also suggests that measurement stations are frequently constructed where pollution is a real or suspected issue, which introduces a source of bias. Lieb (2003) also proposes that constructing monitoring stations is in itself a form of bias because it demonstrates a political system determined to combat pollution.

Lieb (2003) submits a host of other problems with equation (1): 
- The potential for a simultaneity bias

- A disregard for other functional forms that may provide more appropriate specification

- A potentially problematic use of a time trend

- Multicollinearity

- The effect of income on pollution may not be immediate, but, instead, lagged

- Differently sloped coefficients in different countries due to the presence heterogeneity

We do not find it instructive to elaborate on these problems in this paper. They are certainly worth noting, however, and will be kept in mind in our subsequent analyses. For a more detailed treatment of the above issues, see Lieb (2003). Finally, collection of environmental data is still fairly novel; for collection of relevant indicators started in the 1960s at the earliest. This makes time-series applications particularly challenging (Lieb, 2003).

Another critique revolves around the estimation of the turning point - the level of income at which per capita GDP growth begins to improve environmental quality. There is nowhere near a clear-cut consensus in terms of turning points. Peak estimates range from $\$ 3,300$ to $\$ 16,000$ in per capita GDP for particulate matter and smoke, from $\$ 3,000$ to $\$ 13,400$ in per capita GDP for $\mathrm{SO}_{2}$, from $\$ 5,500$ to $\$ 21,800$ in per capita for $\mathrm{NO}_{\mathrm{x}}$, from $\$ 6,200$ to $\$ 21,800$ in per capita GDP for $\mathrm{CO}$, and from $\$ 13,000$ to $\$ 35,000$ in per capita GDP for $\mathrm{CO}_{2}($ Moomaw and Unruh, 1997 in Anderson and Cavendish, 2001). Variations among pollutants are to be expected; for if countries are rational actors, they will attempt to combat more harmful and immediate pollutants at lower levels of income. Such variations within estimates of the turning point for a single pollutant are cause for concern. Dinda (2004) sums it up by saying that "there is no agreement in the literature on the income level at which environmental degradation starts declining" (p. 431). To make matters worse, not all researchers agree on the same shaped PIR 
within pollutant type. Lieb (2003) constructs a meta-analysis via a comprehensive table, comparing PIR shapes (EKC, monotonically rising, monotonically falling, N-shaped, insignificant, or not available) and turning point estimates among studies. To illustrate the ambiguity inherent in the PIR literature, consider that, according to Lieb (2003), research has suggested that the PIR for $\mathrm{SO}_{2}$ is either $\mathrm{N}$-shaped, shaped as an EKC, insignificant, or monotonically rising.

Though hinted at above, it is worth clearly elucidating that the traditional approach, detailed in equation (1) above, relies on panel data. Cross-sectional data may also be used, but in this case, one must assume that each country in the sample follows the same PIR path-a large assumption to make. Panel data can account for unobserved heterogeneity among countries, but the corresponding regression analyses can still be problematic: "Such estimates do not guarantee that over time individual countries will move along the estimated relationship (de Bruyn et al., 1998). The results of panel countries and that of individual or subsample countries vary widely (Dijkgraaf and Vollebergh, 1998; Stern and Common, 2001)" (Dinda, 2004, p. 446). Further, de Bruyn et al. (1998) "argue that conventional cross-section estimation techniques have generated spurious estimates of the environmental Kuznets curve because they do not adequately capture the dynamic process involved" (in Dasgupta et al., 2002). In our opinion, there have not been enough time-series studies to examine and analyze the EKCs, or other PIR forms, of individual countries. This relates back to the problem of data availability.

Two final critiques, without much elaboration, follow. The employment of reduced form modeling may prohibit understanding of the causes of EKCs (Dinda, 2004). Lastly, "[a] number of relevant factors have so far been omitted in the EKC studies, such as transboundary and intergenerational externalities" (Ansuategi et al., 1998; Copeland, 1996 in Dinda, 2004). 
Accounting for these two forms of externalities in particular presents an immense challenge for researchers. Because of the possibilities of externalities unaccounted for, it is wise for audiences of all PIR studies to be wary and cautious in interpreting results. Again, we do not intend to elaborate on the aforementioned criticisms in this paper, but will take them into consideration in our subsequent analyses. Furthermore, note that our subsequent analysis does not overcome every single criticism outlined above; however, as researchers interested in spreading a better understanding of the environmental issues at hand, we do feel that our research has insight to offer. We also think that it is useful to present a list of potential problems that can arise in EKC research to better inform future researchers and to encourage a thoughtful reading of our paper and all EKC papers in general. For a more complete analysis of the particular issues detailed in this paragraph, we refer you to Dinda (2004).

In this paper, we aim to add to, and hopefully bring some clarity to, the vast amount of EKC literature, which we have seen is nowhere near consensual. We begin with an EKC-related literature review. Next, we discuss our data by presenting descriptive statistics and describing our sources. We follow by describing our empirical approach, in which we are primarily concerned with average PIR behavior, though we do touch upon the behavior in individual countries. We then present our results before concluding.

\section{Literature Review}

The first empirical study dealing with the EKC dates back to 1991. In 1991, Grossman and Krueger wrote a paper analyzing the environmental impacts of a North American Free Trade Agreement that laid a foundation for the literature to come. Some would argue, though, that the seminal paper on the topic is in fact Grossman and Krueger (1995). In the paper, the authors analyze the effect of increases in income and wealth on four types of environmental indicators- 
urban air pollution, oxygen regime in river basins, fecal contamination of river basins, and contamination of river basins by heavy metals. The authors conclude that the turning points for the different pollutants vary, but that, in most circumstances, they precede a country reaching per capita income of $\$ 8,000$ (1985 USD). The authors' approach is quite straightforward; they regress data on the pollutant of interest taken from across the world on a polynomial in GDP per capita and other country characteristics, also including lagged GDP per capita terms (Levinson, 2008). ${ }^{1}$ The researchers then declare — as evidenced by plots of the regression results - that there is evidence of an inverted-U shaped curve (i.e. a Kuznets effect). In their 1995 paper, Grossman and Krueger offer a noteworthy piece of advice to all interested in researching the environmenteconomic growth relationship: "Each of these dimensions of environmental quality (and others) may respond to economic growth in a different way. Therefore, a study of environment and growth should aim to be as comprehensive as possible" (p. 355). As do many of the authors who write on the EKC relationship, Grossman and Krueger present a theoretical lens in their paper. The first theory that they propose is intuitively appealing and conforms to economic theory surrounding the demand for normal goods. If environmental quality is a normal good, as the income of a country increases, the demand for environmental quality will also increase. Thus, as people become more aware of the environment, environmental regulation is implemented and becomes more strongly enforced. Consequently, Grossman and Krueger (1995) posit that "[a]s nations or regions experience greater prosperity, their citizens demand that more attention be paid to the noneconomic aspects of their living conditions" (p. 372). The authors also outline another theory, suggesting that it is possible that as countries experience economic growth, they

\footnotetext{
${ }^{1}$ The World Bank (1992) was also instrumental in popularizing a similar approach.
} 
halt production of pollution-intensive goods, and instead begin to import these goods from other countries with less restrictive environmental regulation (Grossman and Krueger, 1995, p. 372).

In a survey of the EKC literature, Dinda (2004) also presents theoretical support for an EKC relationship. Like Grossman and Krueger (1995), Dinda (2004) discusses a preference for environmental quality at higher levels of income. The curvature may also stem from the fundamental flow of an advancing economy, as seen in Figure 1.

\section{Figure 1: Economic Shifts Accompanying Growth}

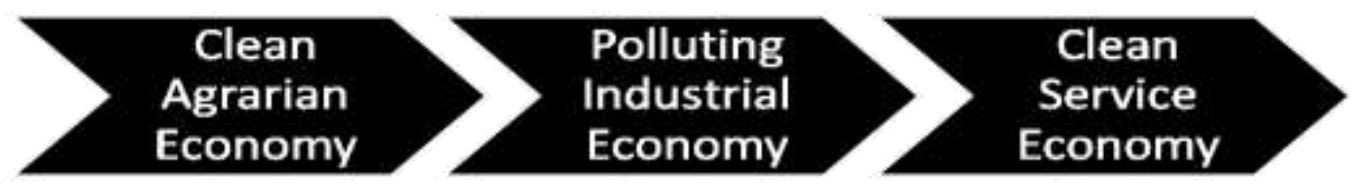

Adapted from: Dinda, S. (2004, July 14). Environmental Kuznets Curve Hypothesis: A Survey. Ecological Economics, 49, pp. 431-455.

Dinda (2004) presents a host of other factors that may be responsible for the inverted-U shape of the EKC. ${ }^{2}$

In the 2004 paper, Dinda also makes the observation that "there is no agreement in the literature on the income level at which environmental degradation starts declining" (p. 431). Even more powerfully, the author suggests that "[e]vidence for the existence of EKC is inconclusive" (p. 450). The survey also breaks environmental indicators used in other studies into three broad categories: air quality, water quality, and other environmental quality indicators. The paper outlines a major flaw in certain EKC studies - that being "certain studies assume that each country should follow EKC with same shape but level of the curve may vary across countries as per their economic position. The social and political factors are also crucial for

\footnotetext{
${ }^{2}$ For a detailed list of possible factors, refer to Appendix 1.
} 
shaping the EKC" (Dinda, 2004, p. 442). To this point, Barrett \& Graddy (2000) argue that for a number of environmental indicators, improvements in civil and political freedoms significantly better environmental quality. Findings suggest that political reforms may, perhaps, be more important than economic reforms in terms of environmental improvement.

Similarly, Lieb (2003) writes extensively on the state of the EKC literature. Lieb (2003) states that "[f]our causes of a time series EKC are empirically validated: rising demand for environmental quality, substitution between pollutants, technological progress, and increasing returns to scale in abatement" (p. 2). The author also suggests that in order for a country to experience a Kuznets effect with a specific pollutant, the government must play a role in environmental regulation via policy measures, else the PIR would perpetually rise. In a literature survey, Yandle et al. (2002) echo (and elaborate upon) this claim, writing "[i]f economic growth is good for the environment, policies that stimulate growth (trade liberalization, economic restructuring and price reform) ought to be good for the environment" (p. 17). Similar to other studies, Lieb (2003) suggests that the EKC exists, but only for some pollutants and not in all countries alike. Lieb (2003) writes that most researchers now include a cubic term in EKC equation, which was first proposed by Shafik and Bandyopadhyay (1992), to allow for asymmetry in the curve. Lieb (2003) also suggests that most studies agree that an EKC exists for the air pollutants $\mathrm{SO}_{2}, \mathrm{SPM}, \mathrm{NOx}, \mathrm{CO}$, lead, and VOC. ${ }^{3,4}$

\footnotetext{
${ }^{3}$ A large portion of Lieb (2003) deals with theory behind the EKC-following-pollutants and non-EKC-following pollutants. As our paper is intended to be more applied in nature, we refer you to Lieb (2003) for further theoretical reading.

${ }^{4}$ Lieb executes a meta-analysis, which provides empirical evidence for a host of different PIR relationships (EKC, monotonically rising, nonotonically falling, $n$-shaped, and insignificant). There are several cases in which separate researchers have suggested several different PIR curves for the same pollutant. This brings to light the disagreement inherent in the EKC literature.
} 
Shafik and Bandyopadhyay (1992) (mentioned above) share an intriguing finding in their World Development Report background paper. The authors ascertain that policy actions tend to be taken where there are generalized local costs and significant private and social benefits. On the contrary, there are few incentives to alter damaging behavior where the costs of environmental harm are borne by others. This is an intuitively appealing relationship that presents researchers and other interested parties with insight into environmental policy. The researchers also posit that macroeconomic policy variables seem to have little effect on the environment. This is not as intuitively appealing and the effect is different than that in the aforementioned environmental policies.

There have been a number of EKC studies that have deviated from the aforementioned typical approach. For instance, Anderson and Cavendish (2001) studied the EKC specifically in the context of policy analysis, with a particular emphasis on technical progress. They move beyond the static approach using dynamic simulation techniques, while factoring in technological development over time, lags, changing preferences, environmental non-linearities, non-linearities in the abatement efficiencies, and the costs of the pollution control methods . The fundamental conclusion reached in the paper is that the gap between initiation of a policy and its effects is lengthy, but not so lengthy as implied by the literature on the EKC.

More recently, Egli and Steger (2007) present evidence for an N-, or possibly M-, shaped curve using a dynamic model developed to analyze the PIR turning point as well as the effectiveness of public policy measures aimed at environmental improvement.

In contrast to Anderson and Cavendish (2001) and Egli \& Steger (2007), Andreoni and Levinson (2001) rely on the traditional static approach in their analysis. Simplification seems to 
be a central tenet of their paper. The authors suggest that the EKC may stem from "simple and natural features of the abatement technology" (p. 283).

As evidenced in some of the literature referenced above, the EKC literature is far from consensual. Empirical evidence is often being updated, revised, and unequivocaly rejected by researchers. Dasgupta, Laplante, Wang, and Wheeler (2002) write that

...recent empirical work has fostered an optimistic critique of the conventional environmental Kuznets curve. The new results suggest that the level of the curve is actually dropping and shifting to the left, as growth generates less pollution in the early stages of industrialization and pollution begins falling at lower income levels..." (p. $148) .^{5}$

Stern (2004) pens a formal critique of the EKC, "[a] new generation of decomposition and efficient frontier models...may lead to the demise of the classic EKC” (p. 1419). Stern (2004) argues that recent evidence, coupled with a changing world, antiquates the classic Kuznets relationship. For Stern (2004) argues: "developing countries are addressing environmental issues, sometimes adopting developed country standards with a short time lag and sometimes performing better than some wealthy countries, and...the $\mathrm{EKC}$ results have a very flimsy statistical foundation" (p. 1419).

\section{The Data}

We collected our pollutant data from the World Development Indicators database. In total, we looked at eight environmental indicators, those being organic water pollutant (BOD) emissions (kg per day per worker), PM10 (micrograms per cubic meter), GEF benefits index for

\footnotetext{
${ }^{5}$ A select graph from (Dasgupta, Laplante, Wang, \& Wheeler, 2002) can be found in Appendix 2.
} 
biodiversity (0 to 100 scale), other greenhouse gas emissions, HFC, PFC, and SF6 (thousand metric tons of $\mathrm{CO}_{2}$ equivalent), nitrous oxide emissions (thousand metric tons of $\mathrm{CO}_{2}$ equivalent), methane emissions ( $\mathrm{kt}$ of $\mathrm{CO}_{2}$ equivalent), forest area (percent of land area), and $\mathrm{CO}_{2}$ emissions (metric tons per capita). Interpretations of the aforementioned indicators are relatively straightforward, with the exception of organic water pollution. Following in the footsteps of Hettige, Mani, and Wheeler (1997), we use biochemoical oxygen demand (BOD) as a proxy for organic water pollution. BOD refers to the amount of oxygen that bacteria in water consume during waste removal processes. The World Bank refers to BOD as a standard watertreatment test for the presence of organic pollutants. In total, there were 214 countries included in the dataset with data spanning 1960-2012. There are missing observations. Selected summary statistics are displayed in Appendix 3.

Data on real GDP per capita, which serves as an explanatory variable in our study, came from the World Penn Tables, composed by Heston, Summers, and Aten (2012). Specifically, we use PPP Converted GDP Per Capita (Chain Series), at 2005 constant prices. Data were available for 190 countries spanning the years 1950-2010. Again, selected summary statistics can be found in Appendix 3.

\section{Empirical Model}

To adequately assess whether there is a consistent PIR relationship-whether an EKC or some other pattern - we felt it would be appropriate to approach the data from three distinct angles: cross-sectional, panel, and time-series. While replicating some of the critiqued approaches above to some extent, we believe that our cross-sectional and panel analyses differ from those of our predecessors in two respects. For one, we have updated data (through 2010 in some cases). Second, we almost unequivocally have the most comprehensive-in terms of years and 
observations - cross-sectional and panel analyses that we have seen. In accordance with the recommendations of other EKC researchers, we experiment with time-series relationshipsthough these are not our primary concern, seeing that we are mainly concerned with average, not country-specific, behavior - corresponding to a number of countries. The countries were selected to represent particular characteristics (i.e. income) and were chosen at our discretion.

Throughout our cross-sectional and panel analyses, which are detailed below, we were particularly interested in the sign of the estimated coefficient on the quadratic term. Referring to equation (1) and excluding the cubic term for sake of simplicity, a negative sign on the quadratic term corresponds to an EKC effect (except for biodiversity, which, under an EKC framework would be expected to initially fall before increasing with economic growth). Adhering to this logic played a fundamental role in our analysis.

To begin our EKC analysis, we estimated two variations of the traditional Grossman and Krueger model.

1. The first variation was specified using cross-sectional data from the years 1960-2010. This first variation had four sub-variations:

$$
\begin{gathered}
\text { (2) } P=\beta_{0}+\beta_{1} Y+\beta_{2} Y^{2}+\mu, \\
\text { (3) } P=\beta_{0}+\beta_{1} \log (Y)+\beta_{2} \log (Y)^{2}+\mu, \\
\text { (4) } \log (P)=\beta_{0}+\beta_{1} Y+\beta_{2} Y^{2}+\mu, \\
\text { (5) } \log (P)=\beta_{0}+\beta_{1} \log (Y)+\beta_{2} \log (Y)^{2}+\mu,
\end{gathered}
$$

where $P$ is a pollutant measure, $Y$ is real GDP per capita, and $\mu$ is the error term. We performed each of these four Ordinary Least Squares (OLS) regressions on each of the eight environmental measures of interest described in the previous section for every year from 1960-2010 (for which data were available). To further elaborate, we included all 
possible level-log combinations. Log transformations allow us to address the notion of a scale change in variables, while in level form, we are able to analyze in terms of differences. We thus consider both overall change in a specific variable and relative change in the variable in our cross-sectional approach.

What follows is a table of the years for which we performed the four specified OLS regressions, filtered by environmental indicator.

\section{Figure 2: Years for Cross-Sectional Regressions}

\begin{tabular}{|l|l|}
\hline Environmental Indicator & $\begin{array}{l}\text { Years for which Cross-Sectional Regression } \\
\text { Analysis were Performed }\end{array}$ \\
\hline Biodiversity & 2005,2008 \\
\hline PM10 & $1990-2010$ \\
\hline NO & $1990,2000,2005,2008,2010$ \\
\hline BOD & $1989-2007$ \\
\hline Forest Area & $1990,2000,2005,2010$ \\
\hline Methane & $1990,2000,2005,2008,2010$ \\
\hline CO2 (metric tons per capita) & $1960-2009$ \\
\hline Other GHG & $1990,2000,2005,2008,2010$ \\
\hline
\end{tabular}

2. The second regression variation comprised of using panel data from the years 1960-2010 (for years in which data were available, which parallels the years detailed in Figure 2). We constructed both a fixed-effects (FE) and a random-effects (RE) model for each of 
the eight environmental indicators of interest, estimating one level-level model and one transformed model:

$$
\begin{gathered}
\text { (6) } P_{i t}=\alpha+\beta_{1} Y_{i t}+\beta_{2} Y_{i t}^{2}+\varepsilon_{i t} \\
\text { (7) } P_{i t}=\alpha+\beta_{1} \log \left(Y_{i t}\right)+\beta_{2} \log \left(Y_{i t}\right)^{2}+\varepsilon_{i t},
\end{gathered}
$$

where $P$ is a measure of pollution, $Y$ is real GDP per capita, $i$ indexes the country, $t$ indicates time, and $\varepsilon$ is the error term.

For each indicator, we chose one of the two models (FE or RE) as our primary model for analysis based on a Hausman test on the level-level model, executed without the inclusion of the quadratic term. The results of these Hausman tests are summarized in Figure $3 .^{6}$

3. After carrying out the two aforementioned approaches, we moved onto the understudied time-series EKC method. Frankly, in relation to the context of our paper (i.e. average behavior) we do not feel that the time-series analysis adds much on top of the crosssectional and panel analyses. We carefully selected four countries to analyze: Brazil, China, Haiti, and the United States. These countries, we feel, are well-known (of interest) and have real GDP per capita statistics that represent points across the spectrum. We experienced one of the problems that other researchers have had with time-series: not enough years of data. We thus limit our time-series analysis to $\mathrm{CO}_{2}$, for which data generally date back to 1960. To search for the presence of an EKC relationship, we solely employed graphical analysis.

\footnotetext{
${ }^{6}$ Note that in both models we neglected to include a cubic term. This was a personal choice made based on the fact that we wished to model the simplest, most straightforward case of a Kuznets Curve. We also used graphical analysis to make this decision and were concerned with overfitting the data.
} 


\section{Figure 3: Hausman Test Results}

\begin{tabular}{|l|l|l|}
\hline Environmental Indicator & Hausman Test p-value & Chosen Model \\
\hline Biodiversity & 0.5421 & Random-Effects \\
\hline PM10 & 0.0198 & Fixed-Effects \\
\hline NO & 0.8403 & Random-Effects \\
\hline BOD & 0.0994 & Random-Effects \\
\hline Forest Area & 0.4504 & Random-Effects \\
\hline Methane & 0.3378 & Random-Effects \\
\hline CO2 (metric tons per capita) & 0.0000 & Fixed-Effects \\
\hline Other GHG & 0.8107 & Random-Effects \\
\hline
\end{tabular}

\section{Results}

The EKC theory is intuitively appealing, but the results produced by our models cause us to question the existence of an environmental Kuznets curve throughout the different parts of the environment in practice.

\section{Cross-Sectional Analysis}

We present our cross-sectional results in graphical form. From our dataset containing the eight pollutant measures over 60 years and accounting for years missing data for certain pollutants, we were able to analyze a total 111 PIR combinations. Furthermore, we analyzed each combination 
using the four specifications detailed above: level-level, level-log, log-level, and log-log. We were interested in the estimated sign of the coefficient on the real GDP squared term. A statistically significant ( $\alpha=0.05)$ negative sign (positive sign for biodiversity), provides evidence of a Kuznets effect with that pollutant in that specific year. Results isolating the coefficient on each and every one of the quadratic terms are presented in Figures 4 through 8.

The cross-sectional results do not provide overwhelming evidence of an EKC effect throughout the environment. Overall, $32.66 \%$ of the quadratic terms correspond to a statistically significant EKC effect, $40.54 \%$ of the quadratic terms are statistically equal to zero, and $26.80 \%$ of the quadratic terms correspond to a statistically significant anti-EKC effect.

\section{Figure 4: Aggregated Cross-Sectional Results}

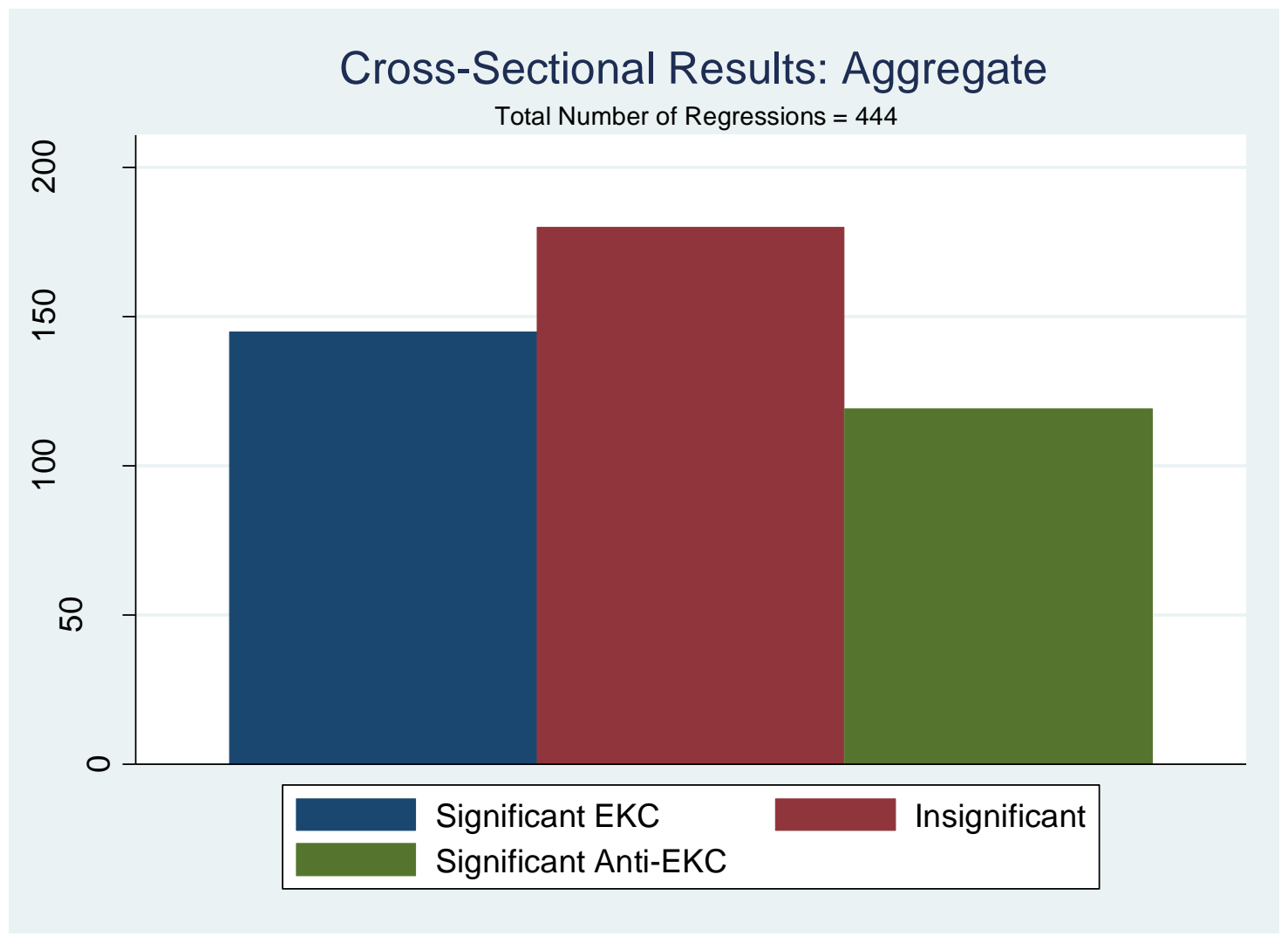


Figures 5-8: Segmented Cross-Sectional Results
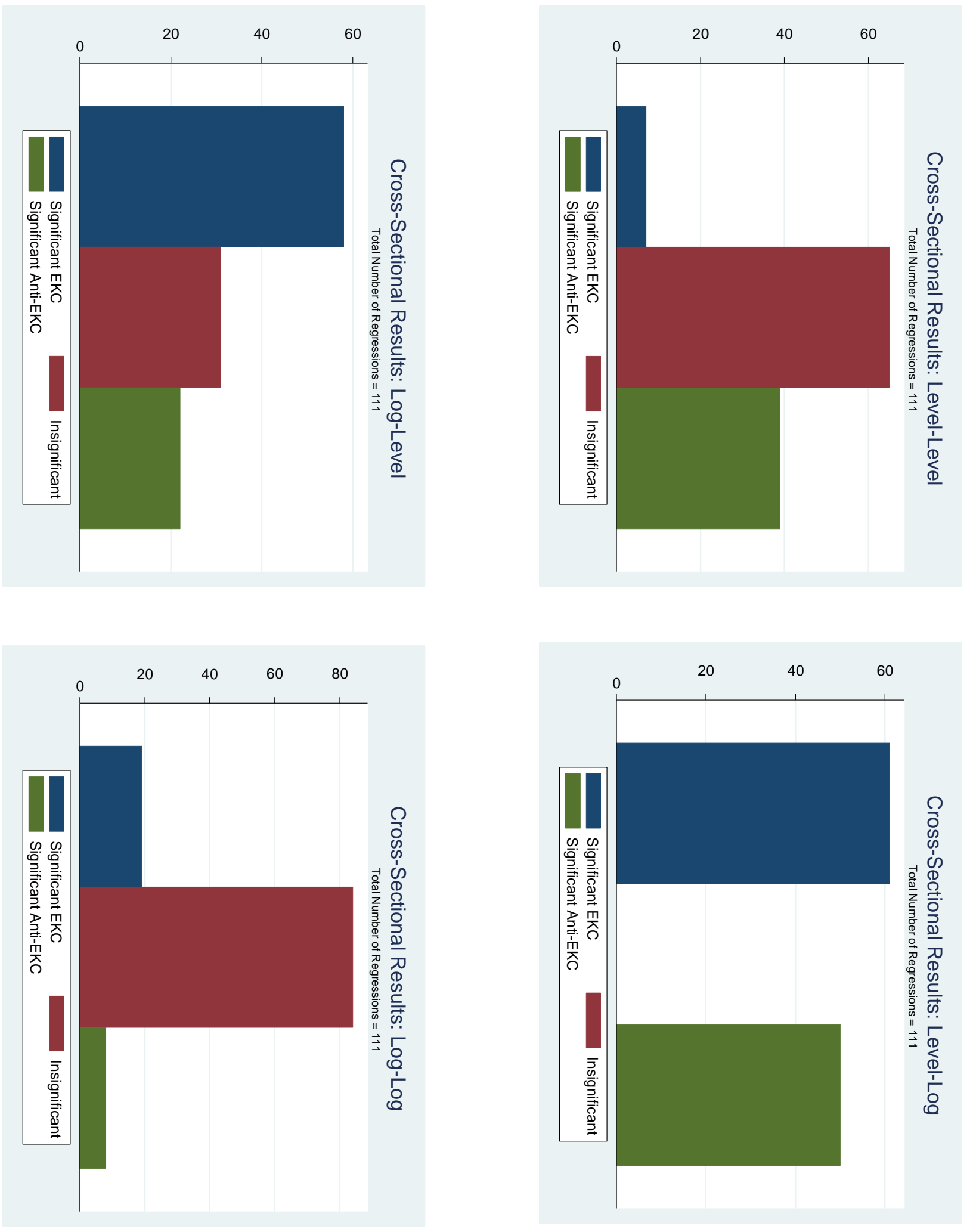
At the individual pollutant level, some pollutants do display more of a consistent statistically significant EKC effect than do others. We were more interested in studying the EKC effect at the environmental level in the cross-sectional analysis. Individual EKCs are addressed more explicitly in the panel analysis section.

\section{Panel Analysis}

Figure 9 illustrates the results of our various panel data regression analyses. In 4 out of $8(50 \%)$ cases without data transformation, the EKC effect is statistically existent at a $10 \%$ level of significance. $^{7}$ In 3 out of $8(37.5 \%)$ cases with $\log (\mathrm{x})$ data transformation, the EKC effect is statistically existent at a $10 \%$ level of significance To determine whether a Kuznets effect is in fact present for a particular pollutant, we find it instrumental to follow a two-step process:

1. First and foremost, we look for a statistically significant quadratic term with the "correct" sign, with "correct" meaning the sign expected if a Kuznets effect were truly present. This step can be completed using Figure 9.

2. Determine whether or not the effect is practically significant. In our analysis, we were admittedly more concerned about the sign of the coefficient estimate (i.e., looking for evidence of some effect), but it is important not to confuse statistical significance with practical significance. If the quadratic term is statistically significant, but the magnitude of the coefficient estimate is so small that the relationship is essentially linear, this is not clear-cut evidence of a Kuznets effect, as outlined by theory. Practical significance is arguably more challenging to detect. It is truly problem-specific. We used turning point

\footnotetext{
${ }^{7}$ The $10 \%$ level of significance was chosen since we were interested in detecting only moderate evidence of an EKC. We figured that if an indicator was statistically insignificant at the $10 \%$ level of significance, this would serve as substantial evidence against an EKC effect. The results presented in Figure 9 are equivalent using a 5\% level of significance, except for the fact that in the case without any data transformation, biodiversity changes from EKC significant to EKC insignificant.
} 
both untransformed and logged real GDP per capita data) analyzed before summarizing. The four pollutant measures in the EKC insignificant category (NO, Forest Area, Methane, and GHG- $\log (\operatorname{rgdp}))$, the pollutant measures in the anti-EKC significant category $\left(\mathrm{PM} 10, \mathrm{CO}_{2}\right.$ $\log (\operatorname{rgdp}))$, and the pollutant measures in the anti-EKC insignificant category (Biodiversity$\log (\operatorname{rgdp})$, PM10-log(rgdp), and Forest Area-log(rgdp)) serve as evidence against a Kuznets relationship.

We now analyze the seven remaining environmental indicators, detailed in Figure 10, in terms of practical significance.

Figure 10: Summary of Statistically Significant Indicators

\begin{tabular}{|c|c|c|c|}
\hline $\begin{array}{l}\text { Environmental } \\
\text { Indicator (units) }\end{array}$ & Transformation & $\begin{array}{l}\text { Coefficient on Quadratic Term ( } 90 \% \\
\text { CI) }\end{array}$ & $\begin{array}{l}\text { Turning Point } \\
\text { Estimate* }\end{array}$ \\
\hline $\begin{array}{l}\text { Biodiversity (Indexed 0- } \\
\text { 100) }\end{array}$ & None & $8.12 \mathrm{e}-10 \quad(3.91 \mathrm{e}-11,1.59 \mathrm{e}-09)$ & $\$ 88,547$ \\
\hline \multirow{2}{*}{$\begin{array}{l}\text { BOD (kg per day per } \\
\text { worker) }\end{array}$} & None & $-1.15 e-11(-1.78 e-11,-5.22 e-12)$ & $\$ 809$ \\
\hline & $\log (\mathrm{X})$ & $-.0046749(-.0066406,-.0027091)$ & $\$ 3,393$ \\
\hline $\begin{array}{l}\mathrm{CO}_{2} \text { (metric tons per } \\
\text { capita) }\end{array}$ & None & $-1.88 \mathrm{e}-09 \quad(-2.14 \mathrm{e}-09,-1.63 \mathrm{e}-09)$ & $\$ 59,309$ \\
\hline $\begin{array}{l}\text { Other GHG (thousand } \\
\text { metric tons of } \mathrm{CO}_{2} \\
\text { equivalent) }\end{array}$ & None & $-3.57 e-06(-5.93 e-06,-1.20 e-06)$ & $\$ 86,264$ \\
\hline $\mathrm{NO}$ & $\log (X)$ & $-3970.539(-5185.666,-2755.411)$ & $\$ 19,186$ \\
\hline Methane & $\log (X)$ & $-7431.878(-10625.33,-4238.425)$ & $\$ 40,424$ \\
\hline
\end{tabular}

*Note: Real GDP per capita is expressed in 2005 USD 
The most convincing case of the presence of an EKC effect is that of organic water pollution. The coefficient estimate is statistically significant in both the untransformed and transformed case. Furthermore, the turning point estimates, particularly in the logged case, are intuitively reasonable. It is reasonable to assume that the EKC applies to this data in practice.

For biodiversity, the turning point estimate of $\$ 88,547$ is extremely high. In fact, in the two years of biodiversity data included in the panel, only 1 of $368(0.27 \%)$ observations has a real GDP per capita value that is at least this large. This would imply, that, in almost all cases, an increase in real GDP per capita would be expected to decrease biodiversity. A similar situation exists in the GHG data. Only 15 of 660 (2.3\%) observations have a real GDP per capita value that is at least as large as that of the turning point.

For $\mathrm{CO}_{2}$, the turning point estimate of $\$ 59,309$ is relatively large as well. In the 50 years of data included in the panel, 623 of 8,205 (7.59\%) observations have a Real GDP per capita value that is at least this large. This would imply, that, for the most part, an increase in real GDP per capita would be expected to be associated with an increase in $\mathrm{CO}_{2}$ emissions. A moderate number of observations, though, would be expected to be on the downward portion of the EKC. Based on the regression, we can say that, in general an increase in real GDP per capita is associated with an increase in $\mathrm{CO}_{2}$ emissions, except at very high levels of income. This is supported by the fact that, empirically,

...the EKC has been observed for pollutants with mainly local and immediate effects such as short-lived air pollutants. It seems that those air pollutants causing the highest health risks are addressed at the lowest income levels...For global and stock pollutants 
such as $\mathrm{CO}_{2}$, however, the PIR for emissions seems to be monotonically rising. ${ }^{9}$ (Lieb, 2003, p. 15-16)

We will summarize by declaring that whether the quadratic effect in the $\mathrm{CO}_{2} \mathrm{EKC}$ estimate is practically significant or not is up to the individual. Figure 6 displays a plot of the estimated regression equation. At $\$ 60,000$, a $\$ 5,000$ increase in income is associated with a 1.13 metric tons per capita decrease in $\mathrm{CO}_{2}$. Relative to the overall mean of 4.2 metric tons per capita, this is a practically significant effect. It is also wise to consider, however, that this is a negligible effect in comparison to the overall sample max of 101.95 metric tons per capita.

\section{Figure 11: $\mathrm{CO}_{2}$ versus Real GDP per Capita Quadratic Fit (Not for a Particular Country)}

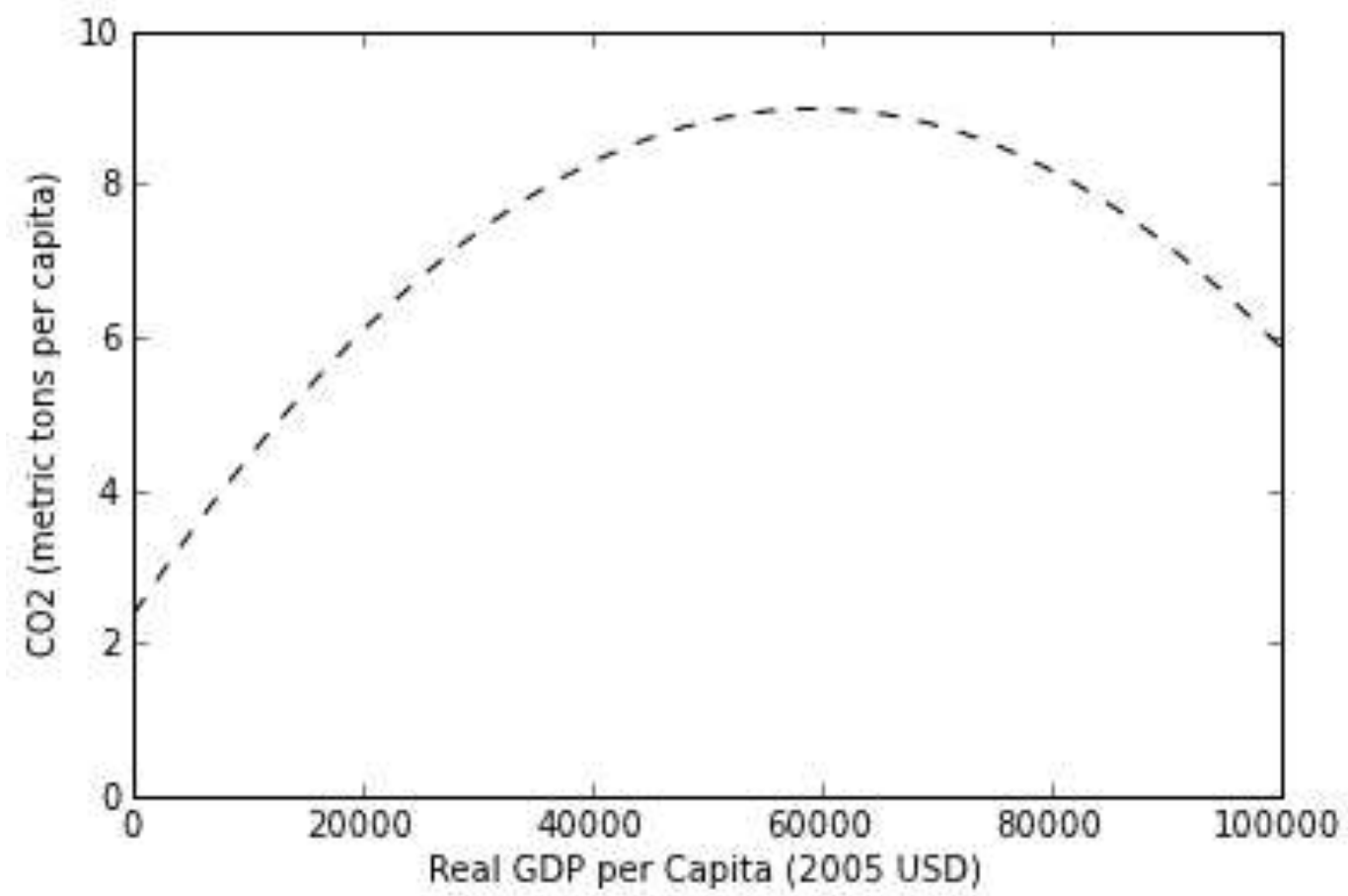

Finally, the case of NO (with logged real GDP per capita data) has a turning point of $\$ 19,186$ (28.8\% of observations have real GDP values above this threshold), while methane has a

\footnotetext{
${ }^{9}$ However, our study contradicts this observation in another regard; for we found an anti-Kuznets effect for PM10.
} 
higher turning point of $\$ 40,024$ (7.7\% of observations have real GDP values above this threshold).

In order to claim that an EKC effect transpires in the environment in general, we would expect consistent statistically significant and practically significant coefficient estimates (with the appropriate signs) for all pollutant measures analyzed. Likewise, in order to make another broad claim - an anti-EKC effect, for example — we would need to see consistent statistically significant and practically significant coefficient estimates (with the appropriate signs relating to the claim) for all pollutant measures analyzed. In our panel results, though we do see some evidence of an EKC for specific pollutant measures, we do not see any sort of consistency supporting either an EKC or an anti-EKC effect for all pollutants.

\section{Time-Series Analysis}

In our opinion, time-series analysis does not add much on top of our panel analysis. In exploring the environmental Kuznets effect, we particularly are more concerned with average behavior over time, rather than the behavior of specific countries. Nevertheless, we did explore the PIR of select individual countries, as illustrated in Figures 12 through 15.

We will conclude our discussion on time-series analysis with a few comments about Figures 12-15. In Brazil and China two developing countries, $\mathrm{CO}_{2}$ emissions essentially parallel real GDP per capita (correlation coefficient equals 0.9595 and 0.9721 , respectively). Admittedly, our plots are not immune to spurious results, but we were mainly interested in visualizing a relationship in individual countries over time. Of the four plots, that of the U.S. appears to be most akin to a full-fledged, inverted-U shaped $\mathrm{EKC}\left(\mathrm{CO}_{2}\right.$ emissions peaked in the 1970s). Under the EKC framework, Brazil and China, two developing nations, seem to both be in the early stages of the EKC, experiencing monotonically rising PIRs. Interestingly, in Haiti, 
Figures 12-15: Select Time-Series Plots
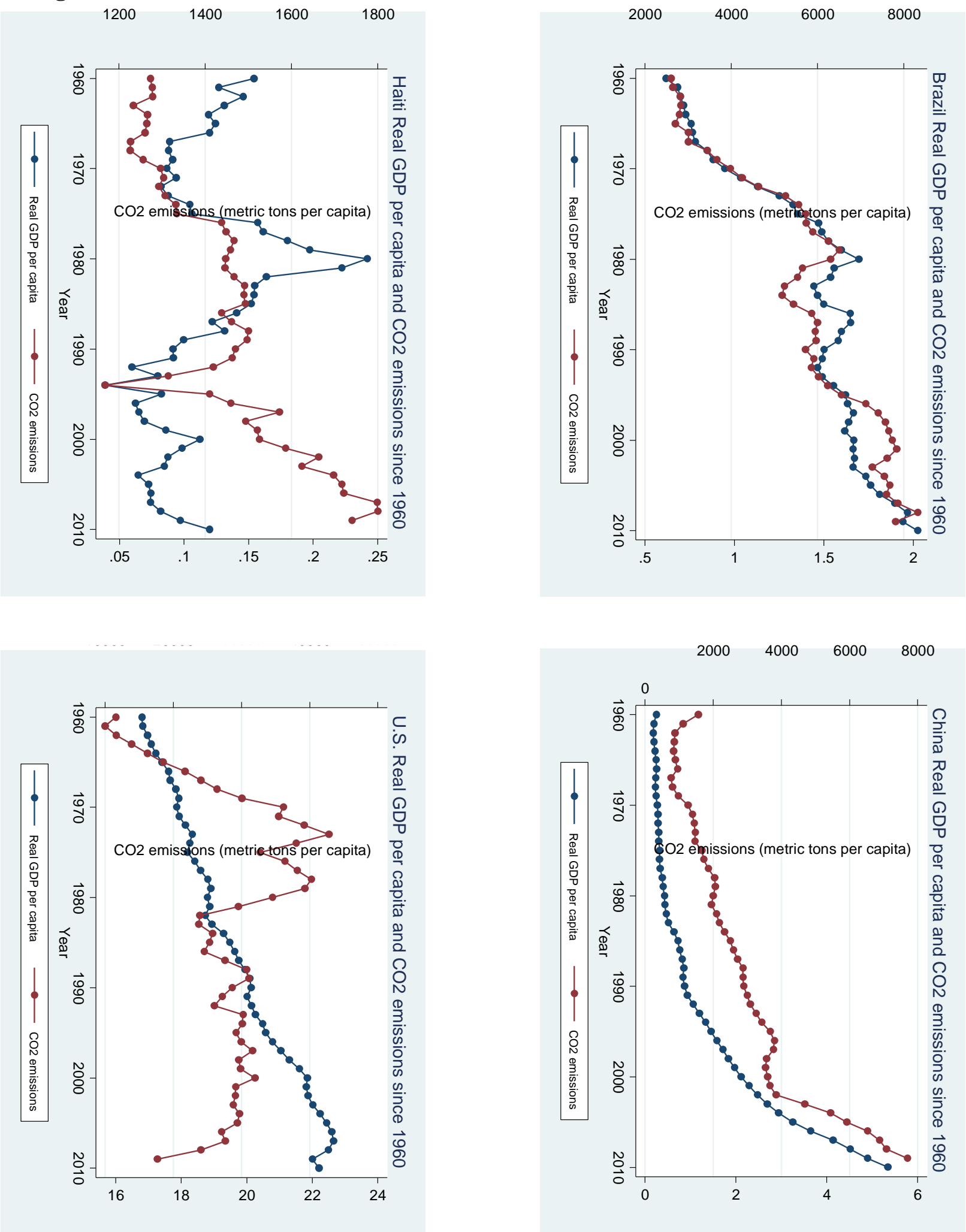
the poorest nation studied in this time-series exercise, the correlation between real GDP per capita and $\mathrm{CO}_{2}$ emissions is negative. Then again, the magnitude of $\mathrm{CO}_{2}$ emissions in Haiti is miniscule (range 0.0389264 to 0.2500827 metric tons per capita).

\section{Conclusions}

Our results suggest that the existence of an EKC relationship throughout the environment should not be taken as given. In other words, the presence of the relationship in practice is not as obvious as it may seem in theory. The absence of a concrete EKC relationship in our results could stem from the fact that the PIR has undergone a change in the early $21^{\text {st }}$ century. This could warrant further research. Though we do not find consistent EKC relationships across all environmental measures studied, we do find evidence of an EKC relationship for specific measures. The clearest example is that of organic water pollution, while $\mathrm{CO}_{2}, \mathrm{NO}$ and methane - and perhaps others, depending on one's judgment —also seem to follow an EKC, though not as clearly as organic water pollution. Interestingly, we have a moderate amount evidence suggesting an anti-Kuznets effect for PM10. ${ }^{10}$

In our paper, we have demonstrated that the PIR does not clearly follow an EKC path, but we have not addressed what the actual path may be. This absolutely warrants further research. As evidenced in the literature review section, there is still no consensus on what shape the PIR takes.

Realizing that there is a need for more time-series work in the EKC literature, we - albeit briefly and inexhaustedly-touched upon specific time-series applications of the PIR. In our research, we aimed to analyze the average PIR, as it applies across the globe. Time-series

\footnotetext{
${ }^{10}$ Refer to Appendix 5 for details.
} 
applications can serve as invaluable tools in analyzing the PIR in specific countries. We would encourage researchers interested in country-specific policy implications of the PIR to pursue more detailed time-series studies. Data unavailability is perhaps the toughest challenge to overcome in time-series analysis of the PIR.

It may also be worthwhile to explore different independent variables, such as a country's GINI coefficient. Perhaps environmental degradation depends more heavily on a different measure of the standard of living than income. Other more subtle influencing factors may also warrant exploration. Research on the PIR should continue to grow, for the issue of environmental degradation is still mainstream and relatively young.

\section{Acknowledgements}

We would like to thank Bryant University's Center for Global and Regional Economic Studies

for giving us the opportunity to perform this research. In particular, we appreciate the work of Dr. Edinaldo Tebaldi, who formally headed this research program and also provided insights into the project. We also thank Dr. Laurie Bates for her help throughout all phases of the project and Dr. Laura Beaudin for her advice. 


\section{Appendixes}

\section{Appendix 1: Factors that may be Responsible for the Inverted-U Shape of the EKC}

- Income elasticity of environmental quality demand

- Scale, technological and composition effects

- International trade

○ Displacement hypothesis

○ Pollution haven hypothesis

$\circ$ FDI

- Race to bottom

○ Diffusion of technology

- International assistance

○ Globalization

- Market mechanism

- Role of price

○ Role of economic agents

- Transition to market economy

Information accessibility

- Regulation

- Formal regulation

Informal regulation

○ Property rights

Adapted from: Dinda, S. (2004, July 14). Environmental Kuznets Curve Hypothesis: A Survey. Ecological Economics, 49, pp. 431-455. 


\section{Appendix 2: EKC Graphical Scenarios}

Figure 1

Environmental Kuznets Curve: Different Scenarios

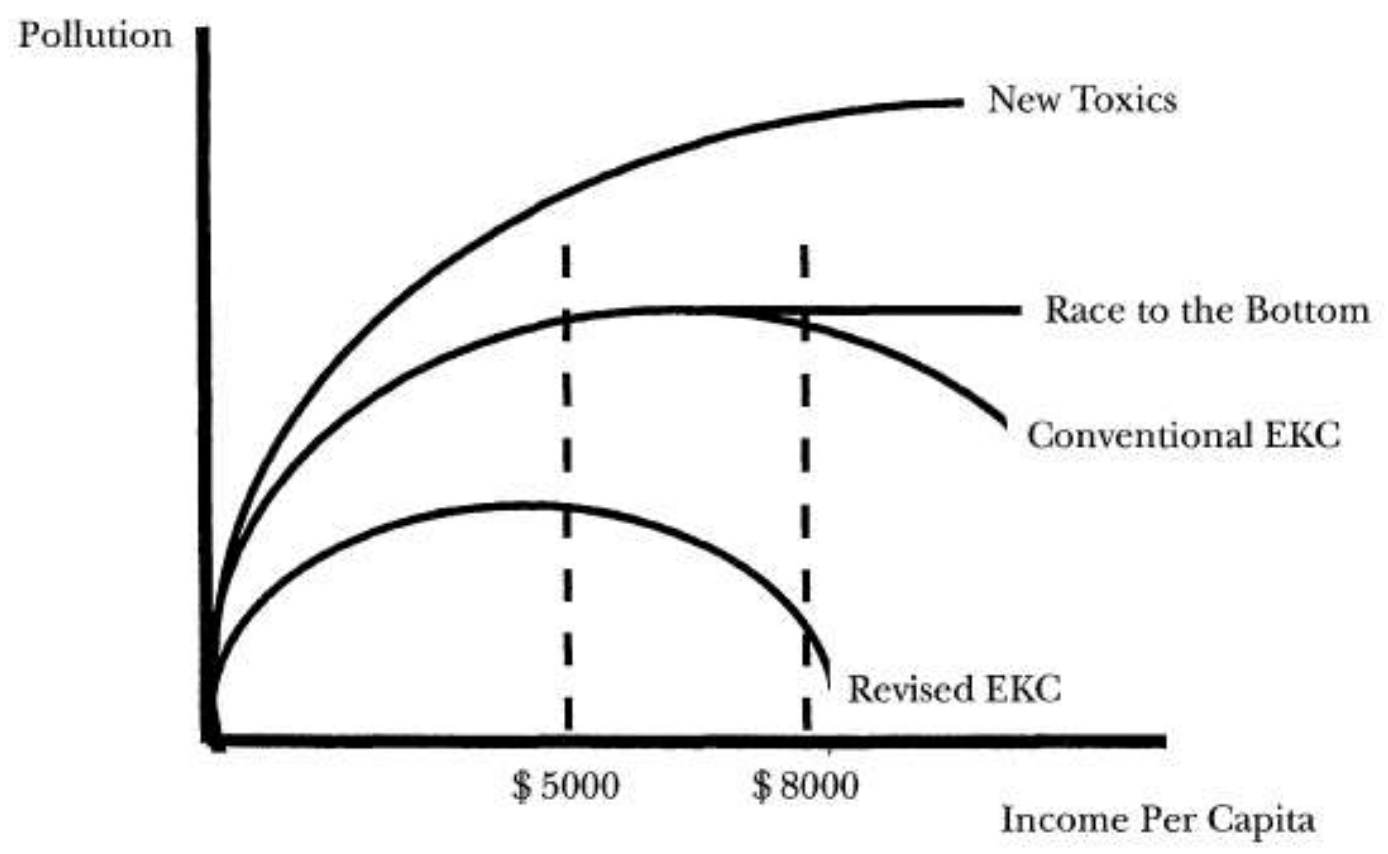

From: Dasgupta, S., Laplante, B., Wang, H., \& Wheeler, D. (2002, Winter). Confronting the Environmental Kuznets Curve. The Journal of Economic Perspectives, 16(1), 147-168. 


\section{Appendix 3: Summary Statistics}

\begin{tabular}{|c|c|c|c|c|c|c|c|c|c|c|}
\hline Years & Statistic & $\begin{array}{l}\text { Real GDP } \\
\text { Per Capita }\end{array}$ & Biodiversity & PM10 & NO & BOD & Forest Area & Methane & $\mathrm{CO}_{2}{ }^{11}$ & GHG \\
\hline \multirow[t]{4}{*}{ 1960-69 } & Mean & $4,708.72$ & . & r. & . & & & & 3.01 & . \\
\hline & Median & $2,284.53$ & · & & . & & & & 0.61 & . \\
\hline & SD & $5,430.08$ & . & . & . & . & . & . & 8.36 & . \\
\hline & $\mathrm{N}$ & 1,128 & 0 & 0 & 0 & 0 & 0 & 0 & 1,484 & 0 \\
\hline \multirow[t]{4}{*}{ 1970-79 } & Mean & $6,728.52$ & . & . & . & & . & . & 4.74 & . \\
\hline & Median & $3,337.82$ & . & . & . & . & . & . & 0.99 & . \\
\hline & SD & $8,710.06$ & . & . & . & & & & 10.18 & . \\
\hline & $\mathrm{N}$ & 1,590 & 0 & 0 & 0 & 0 & 0 & 0 & $1,555.00$ & 0 \\
\hline \multirow[t]{4}{*}{ 1980-89 } & Mean & $8,181.03$ & . & . & . & 0.22 & . & . & 4.00 & . \\
\hline & Median & $4,052.05$ & . & 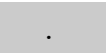 & . & 0.23 & & & 1.21 & . \\
\hline & SD & $10,017.97$ & . & . & . & 0.02 & 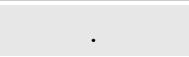 & . & 6.25 & . \\
\hline & $\mathrm{N}$ & 1,614 & 0 & 0 & 0 & 12 & 0 & 0 & $1,560.00$ & 0 \\
\hline \multirow[t]{4}{*}{ 1990-99 } & Mean & $9,634.16$ & . & 67.77 & 19892.47 & 0.18 & 32.10 & 47764.90 & 4.39 & 2250.79 \\
\hline & Median & $4,955.92$ & . & 51.53 & 5353.30 & 0.17 & 28.98 & 11958.90 & 1.74 & 2.40 \\
\hline & SD & $11,562.11$ & . & 50.61 & 45865.80 & 0.05 & 24.32 & 126720.70 & 6.66 & 8884.18 \\
\hline & $\mathrm{N}$ & 1,852 & 0 & 1,702 & 132 & 409 & 182 & 132 & 1,759 & 132 \\
\hline \multirow[t]{4}{*}{ 2000-2010 } & Mean & $12,096.70$ & 7.71 & 46.55 & $20,781.90$ & 0.19 & 31.82 & $52,428.17$ & 4.71 & $5,876.82$ \\
\hline & Median & $6,262.47$ & 1.96 & 36.15 & $5,304.40$ & 0.17 & 30.07 & $13,080.20$ & 2.24 & 274.75 \\
\hline & SD & $14,622.74$ & 16.68 & 34.24 & $56,396.19$ & 0.06 & 23.75 & $149,580.80$ & 6.63 & $29,130.44$ \\
\hline & $\mathrm{N}$ & 2,090 & 368 & 1,892 & 528 & 522 & 558 & 528 & 1,847 & 528 \\
\hline \multirow[t]{4}{*}{ Total } & Mean & $8,742.87$ & 7.71 & 56.59 & $20,604.01$ & 0.19 & 31.89 & $51,495.52$ & 4.21 & $5,151.61$ \\
\hline & Median & $4,137.56$ & 1.96 & 42.48 & $5,320.10$ & 0.17 & 29.77 & $12,894.10$ & 1.32 & 190.15 \\
\hline & SD & $11,319.80$ & 16.68 & 44.07 & $54,422.12$ & 0.06 & 23.88 & $145,218.30$ & 7.71 & $26,389.49$ \\
\hline & $\mathrm{N}$ & 8,274 & 368 & 3,594 & 660 & 943 & 740 & 660 & 8,205 & 660 \\
\hline
\end{tabular}

${ }^{11}$ Strangely, we encountered a single instance of a negative $\mathrm{CO}_{2}$ value in our dataset. The value was -0.020989630 and appeared in 1968. The miniscule value, we think, may be a result of rounding error, calculation error, or entry error. With a total 8,205 observations, we do not think that this affected any result, but would like to remain as transparent as possible. 


\section{Appendix 4: Detailed Panel Regression Analysis Results}

\begin{tabular}{|c|c|c|c|c|c|}
\hline Indicator & Model & EKC Significant* & $\begin{array}{l}\text { EKC } \\
\text { Insignificant** }\end{array}$ & $\begin{array}{l}\text { Anti-EKC } \\
\text { Significant*** }\end{array}$ & $\begin{array}{l}\text { Anti-EKC } \\
\text { Insignificant } * * * *\end{array}$ \\
\hline Biodiversity & Random-Effects & $\mathrm{O}$ & & & $\mathrm{X}$ \\
\hline PM10 & Fixed-Effects & & & $\mathrm{O}$ & $\mathrm{X}$ \\
\hline NO & Random-Effects & $\mathrm{X}$ & 0 & & \\
\hline BOD & Random-Effects & $\mathrm{OX}$ & & & \\
\hline Forest Area & Random-Effects & & $\mathrm{O}$ & & $\mathrm{X}$ \\
\hline Methane & Random-Effects & $\mathrm{X}$ & $\mathrm{O}$ & & \\
\hline $\mathrm{CO}_{2}$ & Fixed-Effects & $\mathrm{O}$ & & $\mathrm{X}$ & \\
\hline Other GHG & Random-Effects & $\mathrm{O}$ & $X$ & & \\
\hline \multicolumn{6}{|c|}{$\begin{array}{l}\text { *EKC Significant denotes a statistically significant quadratic term with a negative sign (except for biodiversity, which, } \\
\text { under the EKC framework, one would expect a positive sign) }\end{array}$} \\
\hline \multicolumn{6}{|c|}{$\begin{array}{l}\text { **EKC Insignificant denotes a statistically insignificant quadratic term with a negative sign (except for biodiversity, } \\
\text { which, under the EKC framework, one would expect a positive sign) }\end{array}$} \\
\hline \multicolumn{6}{|c|}{$\begin{array}{l}\text { ***Anti-EKC Significant denotes a statistically significant quadratic term with a positive sign (except for biodiversity, } \\
\text { which, under the EKC framework, one would expect a negative sign) }\end{array}$} \\
\hline \multicolumn{6}{|c|}{$\begin{array}{l}\text { ****Anti-EKC denotes a statistically insignificant quadratic term with a positive sign (except for biodiversity, which, } \\
\text { under the EKC framework, one would expect a negative sign) }\end{array}$} \\
\hline \multicolumn{6}{|c|}{ Note: $\alpha=0.10$} \\
\hline \multicolumn{6}{|c|}{ O denotes no data transformation prior to regression analysis } \\
\hline \multicolumn{6}{|c|}{$\mathrm{X}$ denotes $\log$ (real GDP per capita) transformation prior to regression analysis } \\
\hline
\end{tabular}




\section{Appendix 5: PM10 Fixed-Effects Regression Table}

\begin{tabular}{lcc}
\hline & $(1)$ & $(2)$ \\
& PM10 & PM10 \\
\hline real_gdp_pc & $-0.00338^{* * * *}$ & \\
real_gdp_pc_sq & $(-17.93)$ & \\
& $1.97 \mathrm{e}-08^{* * *}$ & \\
1_real_gdp_pc & $(12.82)$ & $-46.60^{* * *}$ \\
& & $(-5.04)$ \\
1_real_gdp_pc_sq & & 0.604 \\
& & $(1.09)$ \\
& & $406.8^{* * *}$ \\
& & $(10.63)$ \\
\hline$N$ & $86.28^{* * *}$ & 3568 \\
\hline$t$ statistics in parentheses \\
$p<0.05,{ }^{* * *} p<0.01,{ }^{* * * *} p<0.001$ & $(52.42)$ & \\
\hline
\end{tabular}




\section{References}

Anderson, D., \& Cavendish, W. (2001). Dynamic simulation and environemntal policy analysis: beyond comparative statics and the environmental Kuznets curve. Oxford Economic Papers, 53, pp. 721-746.

Andreoni, J., \& Levinson, A. (2001). The simple analytics of the environmental Kuznets curve. Journal of Public Economcics, 80, 269-286.

Ansuategi, A., Barbier, E., \& Perrings, C. (n.d.). The Environmental Kuznets Curve In: van den Bergh, J.C.J.M., Hofkes, M.W. (Eds.). Theory and Implementation of Sustainable Development.

Barrett, S., \& Graddy, K. (2000). Freedom, growth, and the environment. Environment and Development Economics, 5, pp. 433-456.

Beckerman, W. (1992). Economic growth and the environment: whose growth? Whose environment? World Development, 20, 481-496.

Copeland, B. R. (1996). Pollution content tariffs, environmental rent shifting, and the control of cross-border pollution. Journal of International Economics, 40, 459-476.

Dasgupta, S., Laplante, B., Wang, H., \& Wheeler, D. (2002, Winter). Confronting the Environmental Kuznets Curve. The Journal of Economic Perspectives, 16(1), 147-168.

de Bruyn, S. M., Opschoor, J. B., \& van den bergh, J. (1998). Economic growth and emissions reconsidering the empirical basis of Environmental Kuznets Curves. Ecological Economics, 25, 161-175.

Dijkgraaf, E., \& Vollebergh, H. (1998). ESEE conference. Growth and environment-is there a Kuznets curve for carbon emissions? University of Geneva.

Dinda, S. (2004, July 14). Environmental Kuznets Curve Hypothesis: A Survey. Ecological Economics, 49, pp. 431-455.

Egli, H., \& Steger, T. M. (2007). A Dynamic Model of the Environmental Kuznets Curve: Turning Point and Public Policy. Environmental \& Resource Economics, 36, 15-34.

Grossman, G. M., \& Krueger, A. B. (1993). Environmental impacts of the North American Free Trade Agreement. Garber, P. (Ed.), The U.S. -Mexico Free Trade Agreement.

Grossman, G. M., \& Krueger, A. B. (1995). Economic Growth and the Environment. Quarterly Journal of Economics, 110, pp. 353-378. 
Heston, A., Summers, R., \& Aten, B. (2012, November). Penn World Table Version, 7.1. Retrieved from Center for International Comparisons of Production, Income and Prices at the University of Pennsylvania.

Hettige, H., Mani, M., \& Wheeler, D. (1997, December). Industrial Pollution in Economic Development: Kuznets Revisited. Development Research Group, 1-36.

Kuznets, S. (1955, March). Economic Growth and Income Inequality. The American Economic Review, 45(1), 1-28.

Levinson, A. (2008). Environmental Kuznets curve. In S. N. Durlauf, \& L. E. Blume, New Palgrave Dictionary of Economics (2 ed.). Palgrave Macmillan.

Lieb, C. M. (2003, April). The Environmental Kuznets Curve -- A Survey of the Empirical Evidence and of Possible Causes. Discussion Paper Series, No. 391, 1-60.

Moomaw, W. R., \& Unruh, G. C. (1997). Are Environmental Kuznets curves misleading us? The case of CO2 emissions . Environment and Development Economics, 2, 451-463.

Munasinghe, M. (1999). Is environmental degradation an inevitable consequence of economic growth: tunneling through the environmental Kuznets curve. Ecological Economics, 29, 89-109.

Panayotou, T. (1993). Empirical tests and policy analysis of environmental degradation at different stages of economic development. ILO, Technology and Employment Programme, Geneva.

Pearson, P. J. (1994). Energy, Externalities, and Environmental Quality: Will Development Cure the Ills it Creates? Energy Studies Review, 6(3), 199-216.

Shafik, N., \& Bandyopadhyay, S. (1992). Economic Growth and Environmental Quality: Time Series and Cross-Country Evidence. The World Bank, Office of the Vice President, Development Economics, Washington, DC.

Stern, D. I. (2004). The Rise and Fall of the Environmental Kuznets Curve. World Development, 32(8), 1419-1439.

Stern, D. I., \& Common, M. S. (2001). Is there an environmental Kuznets curve for sulfur? Journal of Environmental Economics and Management, 41(2), 162-178.

World, B. (1992). World Development Report 1992. New York: Oxford University Press.

Yandle, B., Vijayaraghavan, M., \& Bhattarai, M. (2002, May). The Environmental Kuznets Curve: A Primer. PERC Research Study, 02(1), 1-24. 